\title{
Phytochemical screening, and in-vitro antioxidant activities in different solvent extracts of Vitex doniana leaves, stem bark and root bark
}

\author{
James, Dorcas Bolanle ${ }^{1,}$, , Sheneni, Victor Duniya ${ }^{1}$, Kadejo, Olubukola Adetoro ${ }^{1}$, \\ Yatai, Kenneth Bobai ${ }^{2}$ \\ ${ }^{1}$ Department of Biochemistry, Ahmadu Bello University, Samaru Zaria, Nigeria \\ ${ }^{2}$ Department of Biochemistry, Kaduna State University, Kaduna, Nigeria
}

\section{Email address:}

dbjams16187@yahoo.com (D. B James), shenenivictor@gmail (V. Sheneni), Bukkylamenea@yahoo.com (O. A. Kadejo), yataikb@yahoo.com (K. B Yatai)

\section{To cite this article:}

James, Dorcas Bolanle, Sheneni, Victor Duniya, Kadejo, Olubukola Adetoro, Yatai, Kenneth Bobai. Phytochemical Screening, and in-Vitro Antioxidant Activities in Different Solvent Extracts of Vitex Doniana Leaves, Stem Bark and Root Bark. American Journal of Biomedical and Life Sciences. Vol. 2, No. 1, 2014, pp. 22-27. doi: 10.11648/j.ajbls.20140201.14

\begin{abstract}
Phytochemical screening and antioxidant activities in different solvent extracts of Vitex doniana leaves, stem bark and root bark was carried out. The extracts were subjected to various chemical test for phytochemical constituents, total phenolic contents were evaluated using Folin Ciocalteu method and their antioxidant activity was assayed through invitro radical scavenging activity using DPPH· assay, phytochemical screening of this study indicate the presence of cardiac glycosides, tannins, flavonoids, saponnins, alkaloids, steroids and terpenoids. The average total phenol content of leaves methanol and leaves ethanol extracts were significantly $(\mathrm{P}<0.05)$ higher when compared with the total polyphenol contents in the acetone and aqueous solvent extracts. In order of effectiveness (IC50) of the plant extracts the potent inhibitors was leaves ethanol extract $(0.227 \mathrm{mg} / \mathrm{ml})$, follow by stem bark ethanol extract $(0.236 \mathrm{mg} / \mathrm{ml})$, the least was the root ethanol extract $(0.567 \mathrm{mg} / \mathrm{ml})$.This shows that Vitex doniana solvent extracts especially the ethanolic leaves extracts may be a potent source of natural antioxidant and it use in the management of diseases associated with oxidative stress is justify.
\end{abstract}

Keywords: Phytochemical, Antioxidant, Vitex Doniana, DPPH, Solvent Extraction

\section{Introduction}

Research has increased all over the world and a large body of evidence has collected to show immense potential of medicinal plants used in various traditional systems [1]. The medicinal value of these plants is related in their phytochemical components which produce definite physiological actions on human body especially in the cellular and metabolic diseases treatment such as diabetes, obesity and cancer. It is well known that the reactive oxygen species (ROS) such as superoxide anion, hydroxyl radical and hydrogen peroxide are highly reactive and potentially damaging transient chemical species. The tissue damage results from an imbalance between ROS-generating and scavenging systems inside the body. The decrease or damage scavenging systems leads to variety of disorders including degenerative disorders of the CNS (central nervous system) such as Alzheimer's disease, cancer, atherosclerosis, diabetes mellitus, hypertension, AIDS and aging [2, 3].

In recent years, there has been a considerable interest in the finding of natural antioxidants from plant materials because synthetic antioxidants have been questioned due to their toxicity [4]. The most important of these natural antioxidants are flavonoids and phenolic compounds [5].

Several herbs have been reported to exhibit antioxidant activity $[6,7]$ and a great potential source of antioxidant are polyphenols $[8,9]$. Solvent and process variables must be carefully chosen to optimize their extraction. The extraction yield and antioxidant activity of the extracts highly depend on the solvent polarity, which determines both quantitatively and qualitatively the extracted antioxidant compounds [10].

Vitex doniana is one of the medicinal plants used in the management of diseases associated with oxidative stress. Presently there is little information about the antioxidant capacity of the different parts of the plant in different solvent system and more so, type of solvent and its polarity 
used in extraction affect the nature and amount of secondary metabolite extracted [11].

Therefore, in this paper, we studied the extraction of polyphenols and the antioxidant activity of aqueous, methanolic, ethanolic and acetonic extracts from Vitex doniana leaves, stem bark and root bark and discussing some results of polyphenols extraction yields and DPPHscavenging activity, as affected by several solvents type. Our study was conducted to optimize the extraction conditions for total phenolic contents using Folin Ciocalteu method.

\section{Materials and Methods}

\subsection{Collection and Identification of Plant Samples}

The present study was conducted between May and July, 2012 in Biochemistry Department, Ahmadu Bello University, Samaru in Zaria of Kaduna state, Nigeria. The leaves and stem-bark and root-bark of Vitex doniana were collected from the Institute of Agricultural Research (IAR) Ahmadu Bello University (ABU), Zaria Kaduna state. The leaves were identified at the herbarium in the Department of Biological Sciences, Ahmadu Bello University Zaria.

\subsection{Treatment of Plant Samples}

The collected plant samples was rinsed in clean water and dried at room temperature for two weeks. Thereafter the dried plant sample was ground into powder using a mortar and pestle, the powder obtained was then used to prepare the extracts.

\subsection{Extraction}

One hundred gram of each of the grounded stem bark, root bark and leaves were weighed into conical flasks and 1000 $\mathrm{ml}$ of each solvent (aqueous, 70\% methanol, 70\% ethanol and $70 \%$ acetone) poured into each of the flasks. The contents of the 2 flasks shaken and the tops covered with aluminium foil and kept at room temperature for 48 hours $(2$ days) after which the extracts was obtained by filtering using a filter paper. The extracts were then concentrated by drying in a water bath maintained at a temperature of $45 \mathrm{oC}$ until brownish black residues were obtained, percentage yield calculated and then the extracts were kept in sealed containers and refrigerated at $2-4^{\circ} \mathrm{C}$ until required.

\subsection{Phytochemical Screening}

The extracts thus obtained were subjected to qualitative phytochemical analysis following the methods described by Sofowora [12]; Trease and Evans [13].

\subsection{Total Phenolics Determination}

The total phenolic content was determined following the method of Amin et al, [14]. The Folin-Ciocalteu reagent was diluted 10 times $(2.5 \mathrm{ml})$ and mixed with $2 \mathrm{ml}$ of saturated sodium carbonate $(75 \mathrm{~g} /$ litre $)$ and $6050 \mu \mathrm{l}$ of sample and homogenized for 10 seconds and heated for 30 minutes at $45^{\circ} \mathrm{C}$. The absorbance was measured at $765 \mathrm{~nm}$ after cooling at room temperature. The data obtained was calculated by comparison between a standard curve (212$1062 \mu \mathrm{mol}$ Gallic acid/litre) and the absorbance of each sample. The data obtained were expressed as $\mathrm{mg}$ Gallic acid equivalents per gram of extract.

\subsection{DPPH Radical Scavenging Assay (DPPH)}

The DPPH radical scavenging activity of the plant extracts were assayed by the DPPH radical scavenging activity assay used by Chan et al.[15].

DPPH solution was prepared by dissolving $6 \mathrm{mg}$ of DPPH in $100 \mathrm{ml}$ of methanol. To $1 \mathrm{ml}$ of various concentrations of the extracts $(0.020,0.040,0.060,0.080$, $0.100 \mathrm{mg} / \mathrm{ml}), 2 \mathrm{ml}$ of DPPH solution $(0.1 \mathrm{mM})$ was added. An equal amount of methanol and DPPH served as control.

The mixture was shaken vigorously and was left to stand in dark for $30 \mathrm{~min}$. The absorbance of the resulting solution was measured spectrophotometrically at $520 \mathrm{~nm}$. The experiments were performed in triplicate and the percentage scavenging activity of each extract on DPPH radical was calculated using the following formula:

$$
\text { Scavenging activity }(\%)=\{1-(\text { Absorbance of the sample }) /(\text { Absorbance of the control })\} \times 100
$$

DPPH radical scavenging activities of the extracts were expressed as IC50 values. IC50, the effective concentration of the extract required for 50\% scavenging of DPPH radical was calculated from the graph of scavenging activity plotted against sample concentration.

\subsection{Statistical Analysis}

Experimental results are expressed as means $\pm \mathrm{SD}$. The data was analyzed by an analysis of variance $(p<0.05)$ and the means separated by Duncan's multiple range tests. All statistical analyses were performed using coupled Microsoft Software; basically Statistical Package for Social Sciences (SPSS) Version 16.0

\section{Results}

\subsection{Phytochemical Studies}

From the phytochemical studies, it has evaluated in all extracts remarkable presence of tannins and saponins. Others metabolites and bioactive compounds were identified such as cardiac glycosides, flavonoids, alkaloids. Steroids are present in stem and leaves (methanol and acetone extracts), terpenoids are absent in leaves acetone and stem bark (acetone and aqueous extracts), while anthraquinones are absent in all the extracts (Table 1). 
Table 1. Phytochemical screening of different extracts of Vitex doniana leaves, stem bark and root bark.

\begin{tabular}{|c|c|c|c|c|c|c|c|c|c|c|c|c|}
\hline \multirow[t]{3}{*}{ PHTOTHEMICAL } & \multicolumn{4}{|c|}{ LEAVES } & \multicolumn{4}{|c|}{ STEM BARK } & \multicolumn{4}{|c|}{ ROOT BARK } \\
\hline & $75 \%$ & $75 \%$ & $75 \%$ & А сичоия & $75 \%$ & $75 \%$ & $75 \%$ & А аиови & $75 \%$ & $75 \%$ & $75 \%$ & А аи оич \\
\hline & Methanol & Ethanol & Acetone & Aqueous & Methanol & Ethanol & Acetone & Aqueous & Methanol & Ethanol & Acetone & Aqueous \\
\hline Carbohydrates & + & + & + & + & + & - & + & - & ++ & + & + & - \\
\hline Anthraquinone & - & - & - & - & - & - & - & - & - & - & - & - \\
\hline Cardiac Glycosides & + & ++ & + & + & ++ & + & + & + & + & + & + & \pm \\
\hline Saponins & ++ & ++ & ++ & + & + & + & + & + & + & + & ++ & $\overline{+}$ \\
\hline Steroids & ++ & - & + & - & + & - & + & - & - & - & - & - \\
\hline Tannins & ++ & ++ & + & + & + & + & + & + & ++ & ++ & ++ & $\bar{t}$ \\
\hline Flavonoids & + & + & \pm & + & + & + & \pm & \pm & + & + & \pm & \pm \\
\hline \multicolumn{13}{|c|}{ Alkanoids } \\
\hline Mayers & - & - & - & - & - & - & - & - & - & - & - & - \\
\hline Wagner's & + & - & + & + & - & + & - & + & - & + & + & - \\
\hline Dragendroff's & + & + & \pm & + & + & + & + & + & + & + & + & + \\
\hline
\end{tabular}

$+=$ Present; $-=$ absent, $\pm=$ trace

\subsection{Percentage Yield and Quantitative Estimation of Phenolic Compounds}

Extraction yields obtained using aqueous solvent was higher than those from other solvent extracts, highest yield was in root bark aqueous extract (aqueous root bark $>$ aqueous stem bark $>$ aqueous leaves). The quantitative estimation of phenolic compounds measured as gallic acid equivalents depicted that the concentration of total phenolics was maximum for ethanolic leaves extract $(36.11 \mathrm{mg} / \mathrm{g})$, followed methanolic leaves extract $(35.75 \mathrm{mg} / \mathrm{g})$, the lowest content of $20.42 \mathrm{mg} / \mathrm{g}$ was found in aqueous root extract (Table 2 ).

Table 2. Percentage yields and total polyphenol of different extracts of Vitex doniana leaves, stem bark and root barks.

\begin{tabular}{|c|c|c|c|}
\hline EXTRACTION SOURCE & SOLVENT & YIELD OF CRUDE EXTRACT (\%) & TPC (Mg GALLIC ACID/G EXTRACT) \\
\hline \multirow{4}{*}{ LEAVES } & Aqueous & 12.90 & $30.56 \pm 1.22^{\mathrm{a}}$ \\
\hline & $75 \%$ Methanol & 10.30 & $35.75 \pm 1.72^{b}$ \\
\hline & $75 \%$ Ethanol & 10.10 & $36.11 \pm 3.13^{b}$ \\
\hline & $75 \%$ Acetone & 8.90 & $31.03 \pm 4.49^{\mathrm{a}}$ \\
\hline \multirow{4}{*}{ STEM BARK } & Aqueous & 15.90 & $23.82 \pm 1.42^{\mathrm{a}}$ \\
\hline & $75 \%$ Methanol & 9.90 & $27.73 \pm 4.39^{\mathrm{ab}}$ \\
\hline & $75 \%$ Ethanol & 9.20 & $28.05 \pm 1.22^{\mathrm{ab}}$ \\
\hline & $75 \%$ Acetone & 7.50 & $23.49 \pm 1.33^{\mathrm{a}}$ \\
\hline \multirow{4}{*}{ ROOT BARK } & Aqueous & 17.30 & $20.42 \pm 1.94^{\mathrm{a}}$ \\
\hline & $75 \%$ Methanol & 13.00 & $23.72 \pm 2.60^{a b}$ \\
\hline & $75 \%$ Ethanol & 12.80 & $24.43 \pm 2.04^{a b}$ \\
\hline & $75 \%$ Acetone & 9.20 & $20.66 \pm 2.44^{\mathrm{a}}$ \\
\hline
\end{tabular}

Total polyphenols are expressed as mean \pm SD of triplicate determination.. Values in the same column with different letter subscripts are significantly different $\mathrm{p}<0.05$

Table 3. Percentage inhibition of DPPH at $100 \mu \mathrm{g} / \mathrm{ml}$ and IC50 values of the extracts of Vitex doniana leaves, stem bark and root bark compared to Vitamin $C$.

\begin{tabular}{|c|c|c|c|c|}
\hline EXTRACTS & & Percentage inhibition at $100 \mu \mathrm{g} / \mathrm{ml}$ & IC 50* & EQUATION \\
\hline Vitamin C & & $48.792 \pm 0.008^{\mathrm{h}}$ & 0.113 & $Y=57.97 x+43.47$ \\
\hline \multirow{3}{*}{ Aqueous } & Leaves & $29.952 \pm 0.008^{\mathrm{d}}$ & 0.342 & $Y=79.71 x+22.75$ \\
\hline & Stem & $22.705 \pm 0.008^{b}$ & 0.443 & $Y=77.29 x+15.74$ \\
\hline & Root & $19.807 \pm 0.008^{\mathrm{a}}$ & 0.436 & $Y=89.37 x+11.06$ \\
\hline \multirow{3}{*}{$70 \%$ Methanol } & Leaves & $35.265 \pm 0.008^{f}$ & 0.322 & $Y=67.63 x+28.21$ \\
\hline & Stem & $30.435 \pm 0.014^{\mathrm{d}}$ & 0.347 & $Y=79.71 x+22.36$ \\
\hline & Root & $26.570 \pm 0.008^{c}$ & 0.313 & $Y=108.7 x+15.89$ \\
\hline \multirow{3}{*}{$70 \%$ Ethanol } & Leaves & $40.097 \pm 0.017^{\mathrm{g}}$ & 0.228 & $Y=82.12 x+31.30$ \\
\hline & Stem & $35.748 \pm 0.008^{f}$ & 0.236 & $Y=101.4 x+26.08$ \\
\hline & Root & $27.053 \pm 0.008^{\mathrm{c}}$ & 0.561 & $Y=50.72 x+21.49$ \\
\hline \multirow{3}{*}{$70 \%$ Acetone } & Leaves & $33.333 \pm 0.014^{\mathrm{b}}$ & 0.302 & $Y=82.12 x+25.21$ \\
\hline & Stem & $27.053 \pm 0.008^{\mathrm{c}}$ & 0.409 & $Y=72.46 x+20.38$ \\
\hline & Root & $22.705 \pm 0.008^{\mathrm{b}}$ & 0.401 & $Y=89.37 x+14.15$ \\
\hline
\end{tabular}

*IC50 values were calculated based on triplicate analysis of each plant extracts and represented as $\mathrm{mg} / \mathrm{ml}$. Values are expressed as mean \pm SD for triplicate determination. Values in the same column with different letter subscripts are significantly different $\mathrm{p}<0.05$ 


\subsection{Inhibition of DPPH Radical}

The scavenging ability of different solvents extracts of Vitex doniana for free radicals of 1, 1-diphenyl 1-2-picrylhydrazyl (DPPH) showed remarkable scavenging activities. Ethanol leaves extract showed the highest scavenging activity (lowest $\mathrm{IC}_{50} ; 0.227 \mathrm{mg} / \mathrm{ml}$ ) followed by stem bark ethanol extracts $\left(\mathrm{IC}_{50} ; 0.235 \mathrm{mg} / \mathrm{ml}\right)$. The lowest activity of $0.561 \mathrm{mg} / \mathrm{ml}$ was found in root ethanol extract (Figure 1 to 4 and Table 3).

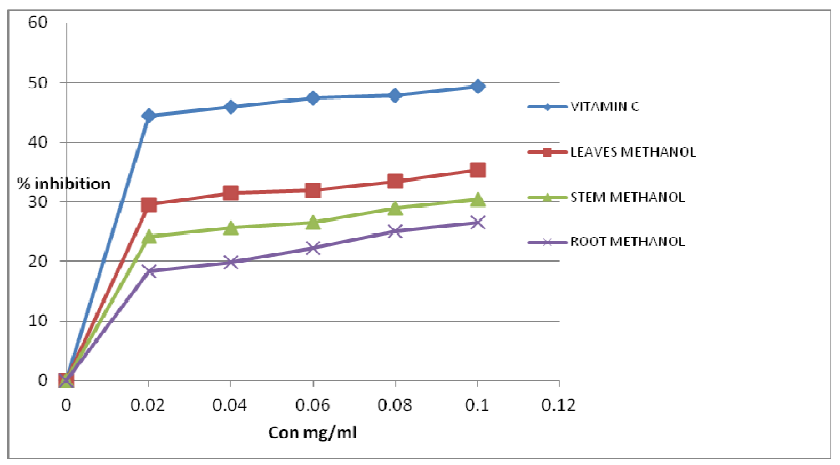

Figure 1. DPPH radical scavenging activity of the $70 \%$ of methanol extracts of leaves, stem bark and root bark Vitex doniana.

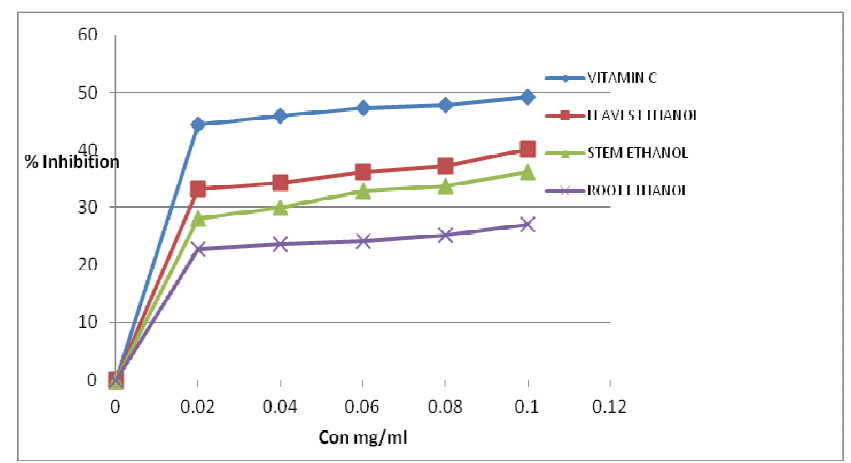

Figure 2. DPPH radical scavenging activity of the $70 \%$ of ethanol extracts of leaves, stem bark and root bark Vitex doniana.

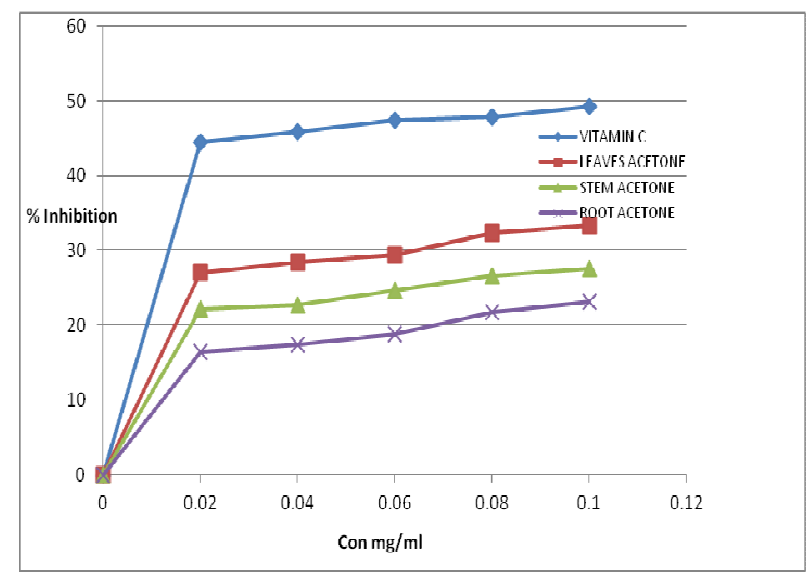

Figure 3. DPPH radical scavenging activity of the $70 \%$ of acetone extracts of leaves, stem bark and root bark Vitex doniana.

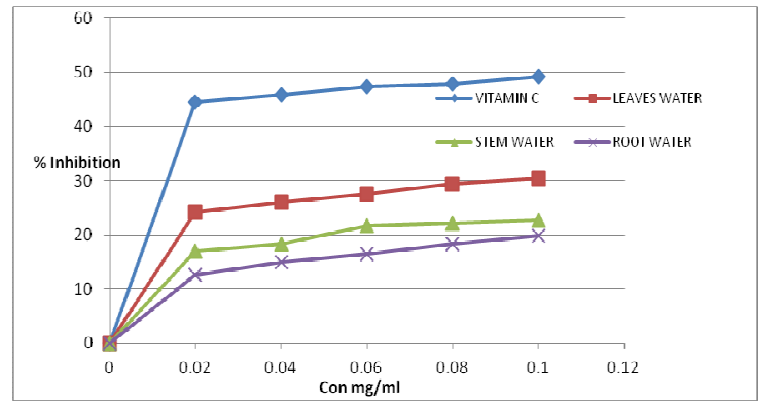

Figure 4. DPPH radical scavenging activity of the aqueous extracts of leaves, stem bark and root bark Vitex doniana and Ascorbic acid.

\subsection{Correlation between Total Phenolic Content and Antioxidant Activities}

DPPH scavenging activity was significantly correlated with phenolics for all the extracts the regression value ranges between $R^{2}=0.758-0.995$ in different extracts (Table 4) and were in the following order aqueous extracts $(0.995)>$ methanol extracts $(0.989)>$ ethanol extracts $(0.977)>$ acetone extracts $(0.758)$.

Table 4. Correlation analysis between total phenolic contents of Vitex doniana extracts and DPPH Radical scavenging activities.

\begin{tabular}{cc}
\hline Type of extracts & Correlation of determination \\
\hline Aqueous & 0.995 \\
$75 \%$ Methanol & 0.989 \\
$75 \%$ Ethanol & 0.977 \\
$75 \%$ Acetone & 0.758 \\
\hline
\end{tabular}

$\mathrm{R}^{2}$ values presented above are all statistically significant $(\mathrm{P}<0.05)$.

\section{Discussion}

The therapeutic effect of various plants extracts in the management of diseases associated with oxidative stress is attributed to their bioactive substances. These bioactive substances which include: alkaloids, tannins, flavonoids, phenols and minerals have been credited biological and medicinal values such as: antiinflammatory, anti-diabetic, antimicrobial, antiatherosclerotic and anti-carcinogenic properties [16]. These phytochemical present in the extracts may be responsible for the folkloric use of Vitex doniana in traditional medicine

Variation in the various extracts yield was due to the polarities of different compounds present in the plants, and such differences have been reported in the literature concerning fruit seeds [17], mulberry leaves [18], and Vietnamese medicinal plants [19]. The highest yield in the sequential extractions was achieved with polar solvents.

All plant phenolic classes have the structural requirements of free radical scavengers and have potential as food antioxidants [20]. In this study, total polyphenols contents of Vitex doniana are express in gallic acid equivalent / gram of extract [21] since gallic acid is one of the major polyphenolic compounds that occur in plants. Plant sample containing high levels of gallic acid or any 
compound equivalent to that may be able to scavenge excessive free radicals such as superoxide anion radicals and peroxyl radicals in the human body and protect cells or tissues against oxidative stress [22].

These results clearly show that the solvent influences the extractability of the phenolic compounds. The phenolic extracts of plants are always a mixture of different classes of phenols, which are selectively soluble in the solvents. The use of an alcoholic solution provides satisfactory results for the extraction process [23]. Alcohol solvents are the best solvents for extraction of phenolic compounds from Vitex doniana leaves, stem bark and root bark. Acetone and water are inefficient solvents for extraction of total phenols from plant part studied. The use of mixture alcohol and water present the advantage of modulating the polarity of alcohol solvents, also adding that solubility of polyphenols depends mainly on the hydroxyl groups, the molecular size and the length of hydrocarbon

DPPH method measure the primary antioxidant activity of plant extracts because it is one of the most effective methods for evaluating the concentration of radicalscavenging materials actively by a chain-breaking mechanism $[24,25]$. There reduction capability of DPPH is determined by the decrease in its absorbance at $520 \mathrm{~nm}$ induced by antioxidants. Results were reported as $\mathrm{IC}_{50}$, which is defined as the amount of antioxidant required to inhibit $50 \%$ of DPPH free radical under experimental conditions $[26,27]$. The extract that required the lowest concentration to positive DPPH test suggest that the samples were free radical scavengers. A high DPPH radical Scanvengers activity is associated with a lower $\mathrm{IC}_{50}$ [28].

In this study, the $\mathrm{IC}_{50}$ result showed that $70 \%$ ethanol leaves extract scavenged 50\% DPPH radicals at the lowest sample concentration and the value of total polyphenol in the ethanol leaves was also the largest of all the extracts, which classify the activities of the ethanol leaves extracts as being a strong antioxidant. Our findings is in agreement with Norshazila et al. [29], and Noriham Abdulla, et al [30] who reported that extracts with high amounts of total phenolic content also showed a high antioxidant activity. According to Barku et al [31], Phenolic compounds generally exhibited significant scavenging effects against the DPPH free radical.

The extraction procedure does affect the total phenolic content and antioxidant activity of the extracts [32]. Various phenolic compounds respond differently in DPPH assay, depending on the number of phenolic groups they have [33]. The responses of phenolics for antioxidant activity estimated by various methods also depend on their chemical structures [34].

Radical scavenging activities is strongly correlated with the total phenolic contents of Vitex doniana extracts. High $\mathrm{R}^{2}$ values for DPPH radical scavenging activity ( 0.758 0.995 ) indicate that at least $76 \%$ of the free radical scavenging activities detected can be attributed to total phenolic contents.

\section{Conclusions}

In conclusions the extracts of leaves, stem bark and root bark of Vitex doniana extracts have shown remarkable scavenging activities and thus prove it traditional uses in the management of diseases associated with oxidative stress. The lowest $\mathrm{Ic}_{50}$ of the ethanolic leaves extracts compared to other extracts suggest to us that this extracts may have more potent antioxidant compared to other extracts.

\section{Acknowledgements}

The work was supported by postgraduate grant from Ahmadu Bello University (Grant No. MSc/ Sci/6145/1112). The author wishes to thank M.r Stephen Jock, M.r John Shaffa and Mr. Yakubu Apeh all of Department of Biochemistry, Ahmadu Bello University Zaria for technical assistance.

\section{References}

[1] Manjula E, Mamidala, E. An ethnobotanical survey of medicinal plants used by traditional healers of Thadvai, Warangal district, Andhra Pradesh, India. IJMRHS. 2013; 2(1): 40-46.

[2] Halliwell B, Gutteridge JMC. Free radicals in biology and medicine, 3rd Edn London: Oxford University Press New York; 1999,p 246-350

[3] Mantle D, Eddeb F, Pickering AT. Comparison of relative antioxidant activities of British medicinal plant species in vitro. J Ethnopharmacol 2000; 72: 47-51.

[4] Sharma V, Paliwal R, Pracheta, Sharma S. Phytochemical analysis and evaluation of antioxidant activities of hydroethanolic extracts of Moringa oleifera lam pods. J Pharm Res. 2011; 4(2): 554-7.

[5] Kostic DA, Velickovic JM, Mitic SS, Mitic MN, Randjelovic SS, Arsic BB et al. Correlation among phenolic, toxic metals and antioxidant activity of the extracts of plant species from southeast Serbia. Bull. Chem. Soc. Ethop. 2013; 27(2)169-178

[6] Sarang Jain, Ameeta Argal. Evaluation of antioxidant activity of a polyherbal formulation. Asian J Pharm Clin Res. 2012; 5(2):194-195

[7] Mohammedi Z, Atik, F. Impact of solvent extraction type on total polyphenols content and biological activity from Tamarix aphylla (L.) Karst, , IJPBS. 2011; 2: 609-615

[8] Dariusz Kowalczyk, Michał Świeca, Joanna Cichocka, Urszula Gawlik-Dziki. The phenolic content and antioxidant activity of the aqueous and hydroalcoholic extracts of hops and their pellets. J Inst Brew.2013; 119(3):103-110

[9] Balakrishnan N, Mayank Srivastava, Pallavi Tiwari. Preliminary Phytochemical Analysis and DPPH Free Radical Scavenging Activity of Trewia nudiflora Linn. Roots and Leaves. Pak. J. Biol. Sci. 2013; 16: 1403-1406

[10] Kowalczyk, D., Świeca, M., Cichocka, J, Gawlik-Dziki, U. The phenolic content and antioxidant activity of the aqueous 
and hydroalcoholic extracts of hops and their pellets. J Inst Brew. 2013; 119: 103-110. doi: 10.1002/jib.73

[11] Aupam Ghosh, Nandita Chowdhury , Goutam Chandra. Plant extracts as potential moisquito larvacides. Indian J med Res. 2012; 135:581-598

[12] Sofowora A. Medical plant and Traditional Medicine in Africa, 1st Edn., John Wiley \&Son Ltd New York, Chichester, New York, 1982 ISBN-10 p 256.

[13] Trease and Evans WC. Text book of pharmacognosy 12th ed. BacillareTrindal; Estonbol London, U.K; 1993, p 1-59

[14] Amin I, Zamaliah MM, Chin WF. Total antioxidant activity and phenolic content in selected vegetables. Food Chem 2004; 87(4): 581- 586

[15] Chan EWC, Lim YY, Omar M. Antioxidant and antibacterial activity of leaves of Etlingera species (Zingiberaceae) in Peninsular Malaysia. Food Chem 2007; 104(4): 1586-1593.

[16] Chukwuka KS, Ikheloa JO, Okonko IO, Moody JO, Mankinde TA. The antimicrobial activities of some medicinal plants on Escherichia colias an agent of diarrhoea in livestock. Advan. Appl. Sci.Res. 2011; 2: 37-48

[17] Jayaprakasha GK, Singh RP, Sakariah KK. Antioxidant activity of grape seed (Vitis vinifera) extracts on peroxidation models in vitro. Food Chem. 2001; 73: 285290.

[18] Saeedeh AD, Urooj A. Antioxidant properties of various solvent extracts of mulberry (Morus indica L.) leaves. Food Chem 2007; 102: 1233-1240.

[19] Quang-Vinh Nguyen, Jong-Bang Eun. Antioxidant activity of solvent extracts from Vietnamese medicinal plants. JMPR 2011; 5(13), 2798-2811.

[20] Kasote D.M. Flaxseed phenolics as natural antioxidants. Int. food res. J 2013; 20(1):27-34.

[21] Chaouche TM, Haddouchi F, Ksouri R, Medini F, EL-Haci IA, Boucherit Z, et al. Antioxidant Potential of Hydromethanolic Extract of Prasium majus L: An in vitro Study. Pak. J. Biol. Sci.2013; 16: 1318-1323.

[22] Gopakumar Gopinathan Nair, Cherupally Krishnan, Krishnan Nair, "Radioprotective Effects of Gallic Acid in Mice.” Biomed Res Int. Article ID 953079, 2013 vol 2013,:13 pages. doi:10.1155/2013/953079

[23] Zohra Mohammedi. Impact of solvent extraction type on total polyphenols content and biological actalivity from Tamarix aphylla (L). Int. J. Pharm. Biol. 2011; 2(1): 609615

[24] Norshazila S, Syed Zahir I, Mustapha Suleiman K, Aisyah
MR, Kamarul Rahim K Antioxidant Levels and Activities of Selected Seeds of Malaysian Tropical Fruits. Mal J Nutr. 2010; 16(1): 149-159.

[25] José Teixeira, Alexandra Gaspar, E. Manuela Garrido, Jorge Garrido, and Fernanda Borges, "Hydroxycinnamic Acid Antioxidants: An Electrochemical Overview," Biomed Res. Int. Article ID 251754, vol. 2013, 11 pages, 2013. doi: $10.1155 / 2013 / 251754$

[26] Sabina Parajuli, Nirmala Tilija Pun, Shraddha Parajuli, Nirmala Jamarattel-Pandit. Antioxidant activity, total polyphenol and Flavonoid contents in some selected medicinal plant of Nepal. JHAS. 2012; 2(1):27-31.

[27] Muhammad Athar Abbasi, Hina Saleeem,Aziz-ur-Rehman, Tauheeda Riaz and Muhammad Ajaib.Determination of Antioxidant Activity and phytoconstituent screening of Euphorbia heterophylla linn, Br. J. Pharm. Res. 2013; 3(2):202-216

[28] Pattanayak SP, Mitra Mazumder P, Sunita P. Total Phenolic Content, Flavonoid Content and in vitro Antioxidant Activities of Dendrophthoe falcata (L.f.) Ettingsh. Res J Med Plant. 2012; 6: 136-148.

[29] Norshazila S, Syed Zahir I, Mustapha Suleiman K, Aisyah MR, Kamarul Rahim K Antioxidant Levels and Activities of Selected Seeds of Malaysian Tropical Fruits. Mal J Nutr. 2010; 16(1): 149-159.

[30] Noriham Abdullah, Wan Saidatul Syida ,Wan Kamarudin, Zainal Samicho, Khairusy Syakirah Zulkifli, Nurain Aziman. Study on Antioxidant Capacity and Phenolic Content of Various Parts of Wax Gourd (Benincasa hispida). World Appl. Sci. J.2012; 19 (7): 1051-1056.

[31] Barku VYA, Opoku-Boahen Y, Owosu-Ansah E, Mensah EF. Antioxidant activity and the the estimation of total polyphenolic and flavonoid contents of the root extract of Amaranthus spinosus. Asian J. Plant sci. res. 2013; 3(1):6974

[32] Shaida Fariza Sulaiman, Nor Adlin Md. Yusoff, Ibrahim M. Eldeen, Eng Meng Seow, Azliana Abu Bakar Sajak, Supriatno Kheng Leong Ooi Correlation between total phenolic and mineral contents with antioxidant activity of eight Malaysian bananas (Musa sp.) J Food Compos Analy. 2011; 24: 1-10.

[33] Chinedu Prosper Anokwuru, Ijeoma Esiaba, Olusola Ajibaye and Ayobami O. Adesuyi. Polyphenolic Content and Antioxidant Activity of Hibiscus sabdariffa Calyx. Res. J.Med. Plant. 2011; 5: 557-566.

[34] Wen Jie Li, Xian Long Cheng, Jing Liu, Rui Chao Lin, Gang Li Wang, Shu Shan Du et al. Phenolic Compounds and antioxidant activities of Liriope muscari. Molecules. 2012; 17: 1797-1808. 